\title{
Stress Analysis of Laminated Composite and Sandwich Beams using a Novel Shear and Normal Deformation Theory
}

\section{Abstract}

A novel Normal and Shear Deformation Theory (NSDT) for analysis of laminated composite and sandwich beams, taking into account shear deformation as well as normal deformation, is developed. The paper investigates flexural behaviors of thick laminated and sandwich beams under plane stress conditions using NSDT. A generalized displacement-based refined formulation is elucidated with inclusion of various warping functions in terms of thickness coordinates to represent shear and normal deformation effects. These effects become pronounced in thick laminated beams and particularly in sandwich beams with transversely flexible core. Present formulation satisfies the shear stress free surface conditions at the top and bottom surfaces of the beam with realistic through-the-thickness variation of transverse shear stresses. The results obtained are compared with higher order theories available in literature. It is observed that NSDT predicts displacement and stresses accurately compared to other higher order theories.

Keywords: Shear deformation, transverse flexibility, laminated thick beam, sandwich beam, transverse shear stress.

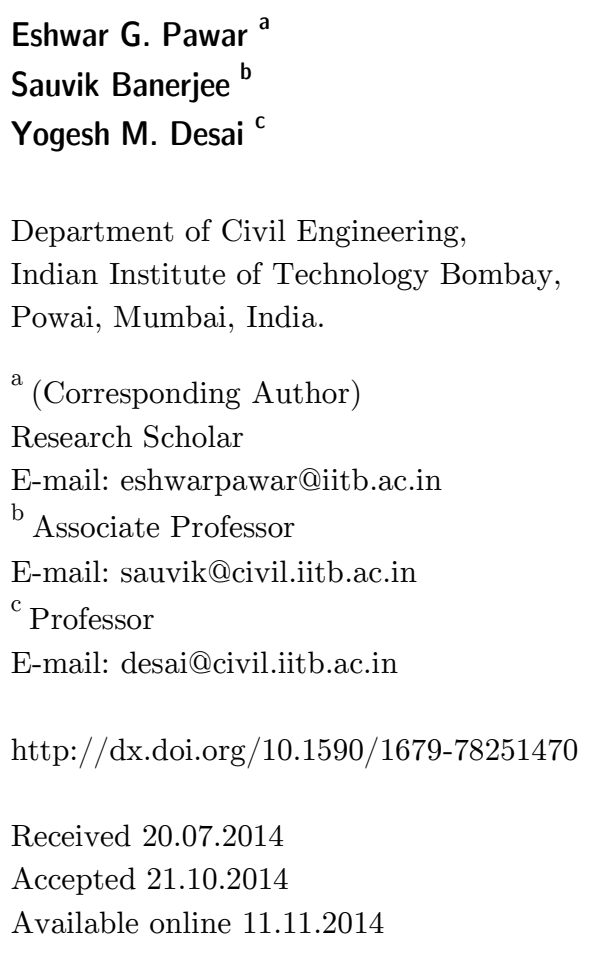

\section{INTRODUCTION}

Laminated composite structures are used in many engineering applications such as aerospace, automotive, and marine engineering. Laminated composites have high strength to weight ratio making it ideal for such applications. In early 18th century Euler and Bernoulli presented Elementary Beam Theory (EBT), which disregard the effect of shear deformation and consequently under predicts deflections and over predicts natural frequencies and buckling load. This results in an inaccurate local as well as global response of the structures. Many efforts have been carried out since last few decades to accurately assess the response of laminated composites. 
Timoshenko (1921) pioneered development of kinematics by allowing linear shear deformation in thickness direction of beams together with rotatary inertia. However, due to kinematics of deformation of the theory, the transverse shear strain is constant through-the-thickness, violating shear stress free surface conditions. Shear correction factor needs to be employed for appropriate representation of strain energy of deformation. It depends on material and geometric properties as well as loading and boundary conditions. Shear correction factor can be eliminated by using proper higher order theories so as to satisfy shear stress free boundaries. Lo et.al. (1977) proposed the expansion of displacement functions in terms of various powers of thickness coordinates. Using this approach, Levinson (1981), Bickford (1982) Khdier and Reddy (1997) presented third order theories for beams. A new class of theories higher than third order was formulated by Kant and Manjunath (1989), Manjunath and Kant (1993). Equivalent single layer, displacement based, strain consistent higher-order shear deformation theory for analysis of symmetric and unsymmetric laminated beams has been used by Zenkour (1999).

To improve the accuracy of the transverse stress prediction, layer-wise higher-order theories based on assumed displacements for individual layers, have been developed and used by Shimpi and Ghugal (1999), Carerra et.al. (2013), Frostig et.al. (1992), Kapuria et.al. (2004). Layerwise theories are layer dependent and the number of degrees of freedom involved is very high and hence these theories computationally complicated.

Bambole and Desai (2007) have formulated hybrid interface finite element for laminated composite and sandwich beams. Each lamina is modeled using hybrid interface element at at the top and bottom lamina interfaces. Desai and Ramtekkar (2002) developed a two dimensional (2D) mixed finite element (FE) model through the thickness of a laminate under the plane stress condition of elasticity using principle of minimum potential energy. Continuity of transverse stresses and displacement fields has been enforced through the thickness direction. Recently, Kant et.al. (2007) proposed semi-analytical method for analysis employing transformation of boundary-value problem to a set of initial value problems.

The classical theories assume that the cross-section normal to the neutral axis remain plane after deformation. It leads to gross error in predicting displacements and stresses in thick beams and laminated composites and become significantly pronounced in case of sandwich beams with transversely flexible core; especially in vicinity of singular conditions like supports and concentrated loads.

It has been observed from the available open literature that many researchers have not incorporated the normal deformability in their formulations. This hypothesis leads the beam sections to be normally unstrained and thereby height of the beams remains unaffected under different support conditions and loading conditions as discussed by Vinson (1975). However, it can be deduced from study of elasticity that under specific load conditions such as concentrated loads or partially distributed loads, the normal deformation in the vicinity of the load is quite high for transversely flexible core as shown by Allen (1969). Comparison of deformation of sandwich beam with stiff core and transversely flexible core is illustrated in Figure 1. 


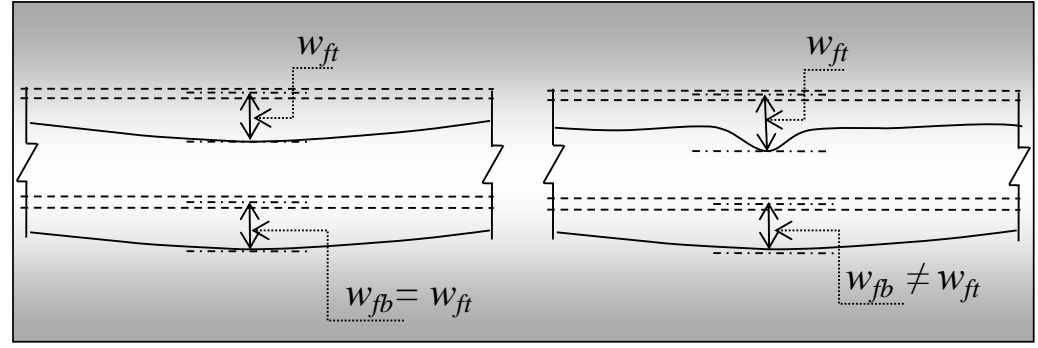

(a)

(b)

Figure 1: Deformation of sandwich beam (a) stiff core and (b) soft core, under localized loads.

In the present work, a novel, generalized Normal and Shear Deformation Theory (NSDT) is developed for incorporating shear deformations as well as normal deformations. The present theory is based on variational principles and consistent formulations are derived accordingly. The mathematical formulation and the solution with appropriate boundary conditions are discussed in the next section. Further, numerical examples are presented for validation and efficacy of the present theory.

\section{THEORETICAL FORMULATION}

The theoretical formulation of a shear deformation theory for beam based on certain kinematical and physical assumptions is presented. The principle of virtual work is used to obtain the governing differential equations and the associated boundary Conditions.

The theoretical formulation of the normal and shear deformation theory (NSDT) for laminated composite and sandwich beams founded on kinematic and physical mechanism with consistent mathematical basis, is presented.

The beam under consideration occupies the region given as: $0 \leq x \leq L ;-b / 2 \leq y \leq b / 2$; and $-h / 2 \leq z \leq h / 2$. Domain of the beam and typical laminate configuration is shown in Figure 2 .

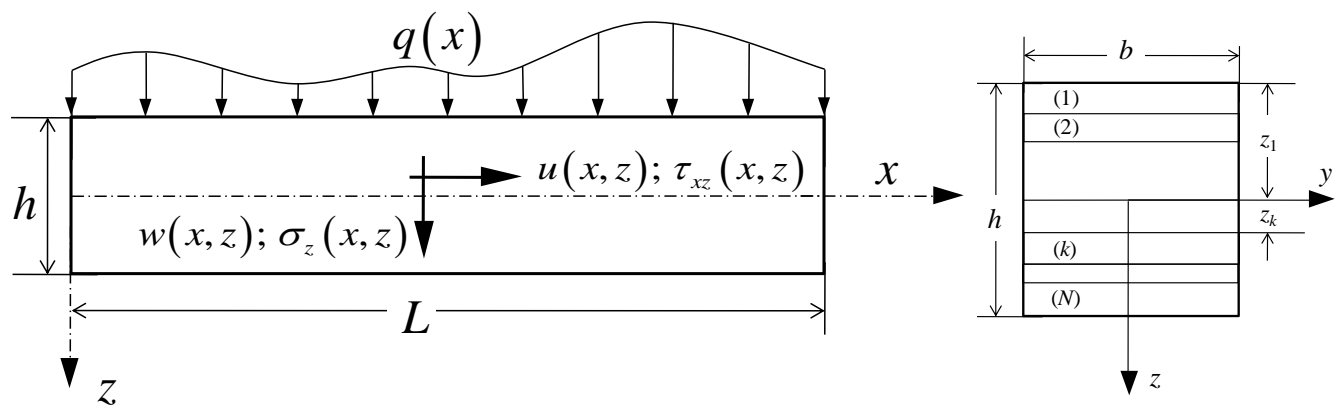

Figure 2: Beam in plane stress condition subjected to transverse loading and its geometry. 


\subsection{Selection of Kinematics}

It is a prerequisite to select a kinematics such that it should satisfy stress-free boundary conditions at the top and bottom of the beam. It is apparent that higher order terms with thickness coordinate needs to be an odd function for pertinent representation of transverse shear stresses through-thethickness of the beam; such that,

$$
f\left(-\frac{z}{h}\right)=-f\left(\frac{z}{h}\right) \text { and } f^{\prime}\left(-\frac{z}{h}\right)=f^{\prime}\left(\frac{z}{h}\right)
$$

Selection of even functions in higher order terms leads to shear traction along the top and bottom surfaces of the beams, violating the conditions of stress-free boundaries.

The generalized displacement field for the present NSDT is given as,

$$
\begin{gathered}
U(x, z)=u_{0}(x)-z \cdot w_{0}{ }_{x}+\left[z \cdot f^{\prime}\left(\frac{1}{2}\right)-h \cdot f\left(\frac{z}{h}\right)\right] \phi(x) \\
W(x, z)=w_{0}(x)+\left[f^{\prime}\left(\frac{1}{2}\right)-f^{\prime}\left(\frac{z}{h}\right)\right] \xi(x)
\end{gathered}
$$

Rewriting,

$$
\begin{gathered}
U(x, z)=u_{0}(x)-z \cdot w_{0},_{x}+\mathbb{F} \cdot \phi(x) \\
W(x, z)=w_{0}(x)+\mathbb{F}^{\prime} \xi(x)
\end{gathered}
$$

where, $U$ is the inplane displacement components in $\mathrm{x}$ direction, and $W$ is the transverse displacement in the $z$ direction. As stated in the foregoing discussion, the function $\mathbb{F}$ can be selected as any appropriate odd function. Specific warping functions used in the present study are enlisted in Table 1.

In case of the present NSDT, it is noteworthy that coefficient of $\xi(x)$ is a derivative of coefficients of shear slopes and its inclusion leads to non-trivial solution of traction-free boundaries.

\subsection{Warping Functions}

Accuracy of a refined theory depends on the selection of the warping function incorporated in the kinematics of the theory. Foremost attempt to include warping function is made by Reissner (1975) with a cubic form. Panc (1975) discussed this theory comprehensively in his monogram on theories of elastic plates. Ambartusmian (1958) presented a different variant of cubic function to represent warping. Levinson (1980) and Murthy (1981) proposed a simplified parabolic warping functions; with later developments by Reddy (1984). Arbind et.al. (2014) developed modified couple stressbased third-order theory for nonlinear analysis of functionally graded beam. Touratier (1991) employed trigonometric functions; whereas Soldatos (1992) used hyperbolic functions and Karama et.al. (2003) used exponential functions to characterize warping of cross-section. 
Albeit several attempts are made to incorporate the warping function, these theories do not consider normal deformability in formulations; which is significant especially in sandwich beams with transversely flexible cores. This paper presents a novel theory which in its generalized form includes warping of cross sections together with normal deformability.

\begin{tabular}{lll}
\hline \hline \multirow{2}{*}{ Model } & \multicolumn{2}{c}{ Warping Functions } \\
\cline { 2 - 3 } & \multicolumn{1}{c}{$\left(z \operatorname{Fosh}^{\prime}(z / h)\right.$} & $\mathbb{F}^{\prime}(z / h)$ \\
\hline NSDT-1 & $(z / 2) \cdot\left(h^{2} / 4-z^{2} / 3\right)$ & $\left(\cosh ^{\prime} \frac{1}{2}-\cosh \frac{z}{h}\right)$ \\
NSDT-2 & $(5 z / 4)\left(1-4 z^{2} / 3 h^{2}\right)$ & $(5 / 4)\left(1-4 z^{2} / h^{2}\right)$ \\
NSDT-3 & $z\left(1-4 z^{2} / 3 h^{2}\right)$ & $\left(1-4 z^{2} / 3 h^{2}\right)$ \\
NSDT-4 & $(h / \pi)(\sin \pi z / h)$ & $\cos (\pi z / h)$ \\
NSDT-5 & $z e^{-2(z / h)^{2}}$ & {$\left[e^{-2(z / h)^{2}}-4 \cdot e^{-2(z / h)^{2}}\left(z^{3} / h^{4}\right)\right]$} \\
\hline \hline
\end{tabular}

Table 1: List of warping functions used in the present NSDT.

Normal and shear strains are obtained within the framework of linear theory of elasticity using the displacement field given by Eq. (5) and (6). These relationships are given as follows:

$$
\varepsilon_{x}=U_{, x}, \quad \varepsilon_{z}=W_{, z}, \gamma_{x y}=\gamma_{y z}=0, \gamma_{z x}=U_{, z}+W_{, x}
$$

Each lamina in the laminate is in a state of plane stress. The constitutive relation for a typical kth lamina is thus written simply as,

$$
\sigma_{i j}{ }^{(k)}=C_{i j}{ }^{(k)} \cdot \varepsilon_{i j}^{(k)}
$$

or,

$$
\left\{\begin{array}{l}
\sigma_{x} \\
\sigma_{z} \\
\tau_{x z}
\end{array}\right\}^{(k)}=\left[\begin{array}{ccc}
C_{11} & C_{13} & 0 \\
C_{13} & C_{33} & 0 \\
0 & 0 & C_{66}
\end{array}\right]^{(k)}\left\{\begin{array}{c}
\varepsilon_{x} \\
\varepsilon_{z} \\
\gamma_{x z}
\end{array}\right\}^{(k)}
$$

where stiffness coefficients $C_{i j}$ are,

$$
\left(C_{11}, C_{13}, C_{33}\right)=\frac{\left(E_{1}, \nu_{13} E_{3}, E_{3}\right)}{\left(1-\nu_{13} \nu_{31}\right)}, C_{66}=G_{13}
$$




\subsection{Governing Equations and Boundary Conditions}

Using the expressions for strains and stresses from equation (6) and (7) in the principle of virtual work, variationally consistent governing differential equations and boundary conditions for the beam under consideration can be obtained. The principle of virtual work when applied to the beam is given as,

$$
b \sum_{k=1}^{n} \int_{z=z_{k}}^{z=z_{k+1}} \int_{x=0}^{x=L}\left[\sigma_{x}^{(k)} \delta \varepsilon_{x}+\sigma_{z}^{(k)} \delta \varepsilon_{z}+\tau_{z x}^{(k)} \delta \gamma_{z x}\right] d x d z-\int_{z=z_{k}}^{z=z_{k+1}} \int_{x=0}^{x=L} q \cdot \delta W d x d z=0
$$

where, symbol $\delta$ denotes the variational operator. Employing Green's theorem in equation (9) successively, we obtain the coupled Euler-Lagrange equations, which are the governing differential equations of the beam and the associated boundary conditions of the beam. The governing differential equations obtained are as follows:

$$
\begin{array}{ll}
\delta u_{0}: & \left(-A_{11} u_{0, x x}+B_{11} w_{0, x x x}-E_{11} \phi_{, x x}-A_{13} \xi_{, x}\right)=0 \\
\delta w_{0}: & \left(-B_{11} u_{0, x x x}+D_{11} w_{0, x x x x}-F_{11} \phi_{, x x x}-B_{13} \xi_{, x x}\right)=q(x) \\
\delta \phi: & \left(-E_{11} u_{0, x x}+F_{11} w_{0, x x x}-H_{11} \phi_{, x x}+A_{66} \phi+\left(A_{66}-D_{13}\right) \xi_{, x}\right)=0 \\
\delta \xi: & \left(A_{13} u_{0, x}-B_{13} w_{0, x x}+\left(D_{13}-A_{66}\right) \phi_{, x}-A_{66} \xi_{, x x}+A_{33} \xi\right)=0
\end{array}
$$

The associated boundary conditions obtained are as below:

At the ends of beam i.e. $x=0$ and $x=a$

$$
\begin{aligned}
& \left(A_{11} u_{0, x}-B_{11} w_{0, x x}+E_{11} \phi_{, x}+A_{13} \xi\right)=0 \quad \text { or } u_{0} \text { is prescribed } \\
& \left(B_{11} u_{0, x x}-D_{11} w_{0, x x x}+F_{11} \phi_{, x x}+B_{13} \xi_{, x}\right)=0 \quad \text { or } w_{0} \text { is prescribed } \\
& \left(-B_{11} u_{0, x}+D_{11} w_{0, x x}-F_{11} \phi_{, x}-B_{13} \xi\right)=0 \quad \text { or } w_{0, x} \text { is prescribed } \\
& \left(E_{11} u_{0, x}-F_{11} w_{0, x x}+H_{11} \phi_{, x}+D_{13} \xi\right)=0 \quad \text { or } \phi \quad \text { is prescribed } \\
& \left(A_{56} \phi+A_{56} \xi_{, x}\right)=0 \quad \text { or } \xi \quad \text { is prescribed }
\end{aligned}
$$

Thus, the variationally consistent governing differential equations and boundary conditions are obtained.

Solution of the set of partial differential equations can be found by converting PDE to simultaneous algebraic equations. The solution should satisfy governing differential equation at every point of the domain for specified boundary and initial conditions of the system. Such a solution can either in form of closed-form or infinite series. Closed-form solutions (CFS) are expressed in terms of finite number of terms.

Following Navier's solution procedure, CFS's to the displacement variables and loading term satisfying boundary conditions can be expressed in following forms,

$$
\left(u_{0}, \phi\right)=\sum_{m=1}^{\infty}\left(u_{0_{m}}, \phi_{m}\right) \cos \alpha x,\left(w_{0}, \xi, q\right)=\sum_{m=1}^{\infty}\left(w_{0_{m}}, \xi_{m}, q_{m}\right) \sin \alpha x
$$

where $\alpha=(m \pi / L)$ and $u_{O_{m}}, w_{O_{m}}, \phi_{m}, \xi_{m}$ are coefficients, which can be evaluated after substituting in the set of four governing differential equations and solving the resulting simultaneous equations. Converting PDE's to simultaneous algebraic equations, by substituting CFS's, we get, $\underline{K} \cdot \underset{\sim}{u}=\underset{\sim}{q}$ $\in(m=1,3, \ldots \infty)$ 
The elements of stiffness matrix are given as follows,

$$
\begin{aligned}
& K_{11}=A_{11} \alpha^{2} ; K_{22}=D_{11} \alpha^{4} ; K_{33}=\left(A_{66}+H_{11} \alpha^{2}\right) ; K_{44}=\left(A_{33}+A_{66} \alpha^{2}\right) \\
& K_{12}=-B_{11} \alpha^{3} ; K_{13}=E_{11} \alpha^{2} ; K_{14}=-A_{13} \alpha ; K_{23}=-F_{11} \alpha^{3} \\
& K_{24}=B_{13} \alpha^{2} ; K_{34}=\left(A_{66}-D_{13}\right) \alpha \text { and } K_{i j}=K_{j i}
\end{aligned}
$$

\section{ILLUSTRATIVE EXAMPLES}

A computer program incorporating the present methodology has been developed in FORTRAN 90 for analysis of homogeneous, layered beams simply supported on both ends. In order to prove the efficacy of the present theory, various numerical examples have been performed. Results have been compared with elasticity solution wherever available in literature.

Illustrative examples covering simply supported, symmetric and unsymmetric cross-ply laminat-

\begin{tabular}{|c|c|c|c|}
\hline Example & Set & Source & Elastic Properties \\
\hline 1 & MAT-1 & - & $\mathrm{E}=1.0, \quad \nu=0.3$ \\
\hline $2,3,5$ & MAT-2 & Pagano (1969) & $\begin{array}{l}\mathrm{E}_{1}=172.4 \mathrm{GPa}, \mathrm{E}_{2}=6.89 \mathrm{GPa}, \mathrm{E}_{3}=\mathrm{E}_{2} \\
\mathrm{G}_{12}=\mathrm{G}_{13}=3.45 \mathrm{GPa}, \mathrm{G}_{23}=1.378 \mathrm{GPa} \\
\nu_{12}=\nu_{13}=\nu_{23}=0.25\end{array}$ \\
\hline 4 & MAT-3 & Kapuria et.al. (2007) & $\begin{array}{l}\mathrm{E}_{1}=131.0 \mathrm{GPa}, \mathrm{E}_{2}=10.3 \mathrm{GPa}, \mathrm{E}_{3}=\mathrm{E}_{2} \\
\mathrm{G}_{12}=\mathrm{G}_{13}=7.17 \mathrm{GPa}, \mathrm{G}_{23}=2.87 \mathrm{GPa} \\
\nu_{12}=\nu_{13}=0.25, \quad \nu_{23}=0.33\end{array}$ \\
\hline 6 & MAT-4 & Pagano (1969) & $\begin{array}{l}\text { Face sheet } \\
\text { MAT-2 } \\
\text { Core Material } \\
\mathrm{E}_{1}=\mathrm{E}_{2}=0.276 \mathrm{GPa}, \mathrm{E}_{3}=3.45 \mathrm{GPa} \\
\mathrm{G}_{12}=0.1104 \mathrm{GPa}, \mathrm{G}_{23}=\mathrm{G}_{13}=0.414 \mathrm{GPa} \\
\nu_{12}=\nu_{13}=\nu_{23}=0.25\end{array}$ \\
\hline 7 & MAT-5 & $\begin{array}{l}\text { Noor and Burton (1994) } \\
\text { Kapuria et.al.(2004) }\end{array}$ & $\begin{array}{l}\text { Face sheet } \\
\mathrm{E}_{1}=131.1 \mathrm{GPa}, \mathrm{E}_{2}=6.9 \mathrm{GPa}, \mathrm{E}_{3}=\mathrm{E}_{2} \\
\mathrm{G}_{12}=3.588 \mathrm{GPa}, \mathrm{G}_{13}=2.3322 \mathrm{GPa}, \\
\mathrm{G}_{23}=3.088 \mathrm{GPa}, \nu_{12}=\nu_{13}=0.32, \nu_{23}=0.49 \\
\text { Core Material } \\
\mathrm{E}_{1}=0.2208 \mathrm{MPa}, \mathrm{E}_{2}=0.2001 \mathrm{MPa} \\
\mathrm{E}_{3}=0.2760 \mathrm{MPa}, \mathrm{G}_{12}=16.56 \mathrm{MPa} \\
\mathrm{G}_{23}=455.4 \mathrm{MPa}, \mathrm{G}_{13}=545.1 \mathrm{MPa} \\
\nu_{12}=0.99, \quad \nu_{13}=\nu_{23}=0.00003\end{array}$ \\
\hline
\end{tabular}
ed, sandwich beams subjected to transverse loading have been considered for highlighting the salient features of the present theory. Material properties for the examples are tabulated in Table 2.

Table 2: Material properties. 
Normal in-plane stress has no reference to the surface boundary conditions; therefore, it can be directly obtained from constitutive relations. However, with the use of constitutive relations for determination of transverse stresses, the stress boundary conditions on the top and the bottom surfaces of laminated beams are satisfied and interlaminar continuity is not satisfied. This drawback can be overcome by imposing equilibrium equations of elastic continua to evaluate transverse shear and transverse normal stresses. In tensorial notations, it is given as, $\sigma_{i j, j}^{(k)}=0$ for $\mathrm{i}, \mathrm{j}=\mathrm{x}, \mathrm{y}$.

Results reported in the present work are expressed in normalized form for consistent comparison as follows,

$$
\bar{\sigma}_{x}=\frac{b}{q_{0}} \sigma_{x}\left(\frac{L}{2}, \pm h / 2\right), \bar{\sigma}_{z}=\frac{b}{q_{0}} \sigma_{z}\left(\frac{L}{2}, Z\right), \bar{\tau}_{z x}=\frac{b}{q_{0}} \tau_{z x}(0, Z), \bar{u}=\frac{b E_{2}}{q_{0} h} u(0, Z), \bar{w}=\frac{100 b h^{3} E_{2}}{q_{0} L^{4}} w\left(\frac{L}{2}, z\right)
$$

Beam bending is a case of plane stress analysis and is more pertinent when the beam is narrow; whereas cylindrical bending is a plane strain problem, which is a direct reduction of three dimensional solutions to a two-dimensional solution (Pagano (1969)).

Solution to plane strain analysis is sought by considering one of the plane of plate as infinite. Some researchers have compared beam bending results with cylindrical bending of long plate, may be due to paucity of appropriate examples. However, it is opinion of the authors that, since the theoretical foundation of plane stress and plane strain is different, it is imprecise to compare these results; albeit the results of two classes are close.

In order to prove effectiveness of the present theory, numerical investigations have been carried out for following examples with different materials and configurations.

Example 1. Homogeneous isotropic beam with material set MAT-1 (Table 3).

Example 2. Homogeneous orthotropic beam with material set MAT-2 (Table 4).

Example 3. Unsymmetric cross-ply laminated beam $\left(0^{\circ} / 90^{\circ}\right)$ with material set MAT-2 (Table 5).

Example 4. Unsymmetric cross-ply laminated beam $\left(0^{\circ} / 90^{\circ} / 0^{\circ} / 90^{\circ}\right)$ with MAT-3 (Table 6).

Example 5. Three-layered symmetric cross ply laminated beam $\left(0^{\circ} / 90^{\circ} / 0^{\circ}\right)$ with MAT-2 (Table 7$)$.

Example 6. Three-layered symmetric sandwich beam $\left(0^{\circ} /\right.$ core $\left./ 0^{\circ}\right)$ with MAT-4. (Table 8).

Example 7. Three-layered sandwich beam with graphite epoxy faces and soft core with MAT-5 and thickness as $(0.1 \mathrm{~h} / 0.8 \mathrm{~h} / 0.1 \mathrm{~h})$ (Table 9$)$.

The beam is subjected to transverse load, $q(x)$ on surface $z=-h / 2$ acting in the $\mathrm{z}$ direction as defined in equation (13). For single sinusoidal load, $q_{m}=q_{0}$ and $m=1$. Whereas, for uniformly distributed load this coefficient is given as, $q_{m}= \begin{cases}\left(4 q_{0} / m \pi\right) & \text { for } m=1,3,5, \ldots \\ 0 & \text { for } m=2,4,6, \ldots\end{cases}$ 
The illustrated examples are initially analyzed for single sinusoidal load for validation and later all these examples are reanalyzed considering uniform load. The results of converged Fourier series are tabulated.
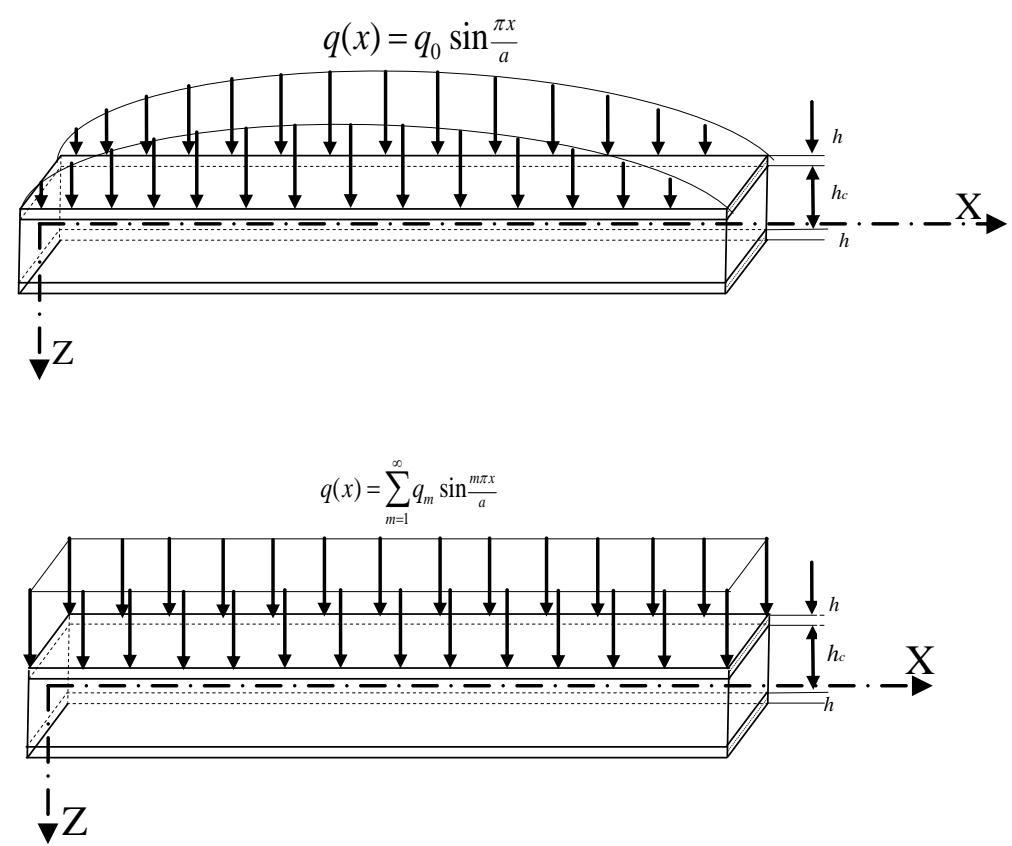

Figure 3: Typical sinusoidal and uniform loading on a layered beam.

\section{DISCUSSIONS}

Exact elasticity solutions for the laminated beams are not available in literature to the best of authors' knowledge. Pagano (1969) has provided solution for long plates under cylindrical bending. As mentioned previously, even though the results of cylindrical bending and beam bending are close, these are altogether different problems. Therefore, semi-analytical solutions given by Kant et.al.(2007) are used for comparison with available examples. Their methodology involves transformation of boundary-value problem to a set of initial value problems and requires higher computational cost. 


\begin{tabular}{|c|c|c|c|c|c|c|c|c|c|}
\hline \multirow{2}{*}{ S } & \multirow{2}{*}{ Theory } & \multicolumn{4}{|c|}{ Sinusoidal Load } & \multicolumn{4}{|c|}{ Uniform Load } \\
\hline & & $\bar{\sigma}_{x}^{\mathrm{TOP}}$ & $\bar{\sigma}_{x}^{\mathrm{BOT}}$ & $\bar{\tau}_{x z}^{\max }$ & $\bar{w}$ & $\bar{\sigma}_{x}^{\mathrm{TOP}}$ & $\bar{\sigma}_{x}^{\mathrm{BOT}}$ & $\bar{\tau}_{x z}^{\max }$ & $\bar{w}$ \\
\hline \multirow{8}{*}{4} & NSDT-1 & -0.6232 & 0.6232 & 0.4745 & 14.1088 & -0.7646 & 0.7646 & 0.6902 & 17.8367 \\
\hline & NSDT-2 & -0.6700 & 0.6700 & 0.4743 & 14.1089 & -0.8251 & 0.8251 & 0.7166 & 17.8366 \\
\hline & NSDT-3 & -0.6719 & 0.6719 & 0.4743 & 14.1089 & -0.8276 & 0.8276 & 0.7166 & 17.8366 \\
\hline & NSDT-4 & -0.6241 & 0.6241 & 0.4766 & 14.1089 & -0.7658 & 0.7658 & 0.6898 & 17.8366 \\
\hline & NSDT-5 & -0.6334 & 0.6334 & 0.4911 & 14.0910 & -0.7775 & 0.7775 & 0.6690 & 17.8145 \\
\hline & NSDT-6 & -0.6409 & 0.6409 & 0.4700 & 14.0383 & -0.7869 & 0.7869 & 0.6691 & 17.7482 \\
\hline & Kant et.al. (2007) & -0.6192 & 0.6223 & 0.4750 & 14.1076 & -0.7625 & 0.7653 & 0.7036 & 17.8356 \\
\hline & Elasticity† & -0.6192 & 0.6223 & 0.4750 & 14.2641 & -0.7625 & 0.7625 & 0.7500 & 17.8516 \\
\hline \multirow{8}{*}{10} & NSDT-1 & -0.6095 & 0.6095 & 0.4772 & 12.6074 & -0.7512 & 0.7512 & 0.7225 & 15.9806 \\
\hline & NSDT-2 & -0.6628 & 0.6628 & 0.4770 & 12.6076 & -0.8175 & 0.8175 & 0.7245 & 15.9809 \\
\hline & NSDT-3 & -0.6686 & 0.6686 & 0.4770 & 12.6976 & -0.8146 & 0.8146 & 0.7259 & 15.9809 \\
\hline & NSDT-4 & -0.6105 & 0.6105 & 0.4770 & 12.6076 & -0.7525 & 0.7525 & 0.7366 & 15.9809 \\
\hline & NSDT-5 & -0.6208 & 0.6208 & 0.4748 & 12.5902 & -0.7652 & 0.7652 & 0.7222 & 15.9589 \\
\hline & NSDT-6 & -0.6289 & 0.6289 & 0.4726 & 12.5389 & -0.7754 & 0.7754 & 0.7800 & 15.8938 \\
\hline & Kant et.al. (2007) & -0.6100 & 0.6100 & 0.4771 & 12.6086 & -0.7525 & 0.7521 & 0.7244 & 15.9823 \\
\hline & Elasticity $\dagger$ & -0.6100 & 0.6099 & 0.4771 & 12.6178 & -0.7520 & 0.7520 & 0.7500 & 15.9813 \\
\hline
\end{tabular}

$\dagger$ Elasticity formulations

Table 3: Normalized transverse displacement $\bar{w}$, inplane normal stress $\bar{\sigma}_{x}$ and transverse shear stress $\bar{\tau}_{x z}^{\max }$ in an isotropic beam under plane stress condition. (Example-1).

Normalized displacement and stresses of thick isotropic beam and orthotropic beam are illustrated in Tables 3 and 4 respectively. Results are shown for aspect ratio 4 and 10. The results are in good agreement with elasticity solution for isotropic beam. The results are compared with semi-analytical solutions.

Tables 5 and 6 illustrate normalized displacements and stresses of beams with lamination schemes as $\left(0^{\mathrm{O}} / 90^{\mathrm{O}}\right)$ and $\left(0^{\mathrm{O}} / 90^{\circ}\right) 2$ respectively (refer Figure 4). For antisymmetric cross-ply laminates, both heterogeneity and anisotropy ratio influences deflections and stresses. This influence of heterogeneity and anisotropy ratio decrease with increase in number of layers. Also, deflections decrease and stresses increase with the number of layers for a fixed anisotropy ratio due to bendingextension coupling. The percentage errors reduce significantly for moderately thick beam. For symmetric laminates bending-extension coupling stiffnesses are zero due to laminate symmetry. Table 7 demonstrates normalized results for three-layered symmetric cross-ply beam. It can be noted from figure 5 that the normalized values of displacements and stresses are in good agreement with the 
results given by Mixed-FEM of Desai and Ramtekkar (2002) and Semi-analytical solutions of Kant et.al. (2007). A large discrepancy in results can be observed with use of higher order shear deformation theory (HOST) of Manjunath and Kant (1993).

The present theory incorporates normal deformation effect in the displacement field and this makes it ideally suitable for beams with low through-the-thickness stiffness like sandwich beams with soft core. In order to study the efficacy of the present theory in this context, the results of two geometrically identical beams under uniform loading and different materials are compared in Table 10. In case of example 6 with MAT-4, Young's modulus of core in transverse direction $\mathrm{E}_{3}$ is $3.45 \mathrm{GPa}$; whereas, in case of example 7 with MAT-5, it is $0.2760 \mathrm{MPa}$. It can be observed that, percentage error for parameters in beam with soft core is significantly reduced. This validates effectiveness of the present theory for beams with normal deformability. Through the thickness variation of normalized transverse shear stress and transverse normal stress is shown in Figure 6.

\begin{tabular}{|c|c|c|c|c|c|c|c|c|c|}
\hline \multirow{2}{*}{ S } & \multirow{2}{*}{ Theory } & \multicolumn{4}{|c|}{ Sinusoidal Load } & \multicolumn{4}{|c|}{ Uniform Load } \\
\hline & & $\bar{\sigma}_{x}^{\mathrm{TOP}}$ & $\bar{\sigma}_{x}^{\mathrm{BOT}}$ & $\bar{\tau}_{x z}^{\max }$ & $\bar{w}$ & $\bar{\sigma}_{x}^{\mathrm{TOP}}$ & $\bar{\sigma}_{x}^{\mathrm{BOT}}$ & $\bar{\tau}_{x z}^{\max }$ & $\bar{w}$ \\
\hline \multirow{9}{*}{4} & NSDT-1 & -0.9159 & 0.9159 & 0.4174 & 1.9392 & -1.0599 & 1.0599 & 0.6132 & 2.4329 \\
\hline & NSDT-2 & -0.9102 & 0.9102 & 0.4167 & 1.9381 & -1.0544 & 1.0544 & 0.6138 & 2.4227 \\
\hline & NSDT-3 & -0.9099 & 0.9099 & 0.4167 & 1.9380 & -1.0510 & 1.0510 & 0.6138 & 2.4227 \\
\hline & NSDT-4 & -0.9174 & 0.9174 & 0.4167 & 1.9381 & -1.0585 & 1.0585 & 0.6138 & 2.4226 \\
\hline & NSDT-5 & -0.9333 & 0.9333 & 0.4095 & 1.9222 & -1.0803 & 1.0803 & 0.6257 & 2.4056 \\
\hline & NSDT-6 & -0.9473 & 0.9473 & 0.4024 & 1.9011 & -1.0981 & 1.0981 & 0.6168 & 2.3817 \\
\hline & HOST & -0.8713 & 0.8713 & 0.4155 & 1.9602 & - & - & - & - \\
\hline & Mixed-FEM & -0.8979 & 0.8455 & 0.4360 & 2.0842 & - & - & - & - \\
\hline & Kant et.al.(2007) & -0.9028 & 0.8469 & 0.4328 & 1.9509 & -1.0461 & 1.0237 & 0.6168 & 2.4300 \\
\hline \multirow{9}{*}{10} & NSDT-1 & -0.6574 & 0.6574 & 0.4678 & 0.7326 & -0.7995 & 0.7995 & 0.7011 & 0.9212 \\
\hline & NSDT-2 & -0.6578 & 0.6578 & 0.4667 & 0.7325 & -0.8000 & 0.8000 & 0.7029 & 0.9212 \\
\hline & NSDT-3 & -0.6578 & 0.6578 & 0.4678 & 0.7325 & -0.8007 & 0.8007 & 0.7029 & 0.9212 \\
\hline & NSDT-4 & -0.6577 & 0.6577 & 0.4677 & 0.7325 & -0.8003 & 0.8003 & 0.7081 & 0.9212 \\
\hline & NSDT-5 & -0.6608 & 0.6608 & 0.4664 & 0.7318 & -0.8031 & 0.8031 & 0.6896 & 0.9204 \\
\hline & NSDT-6 & -0.6637 & 0.6637 & 0.4651 & 0.7303 & -0.8061 & 0.8061 & 0.7054 & 0.9186 \\
\hline & HOST & -0.6741 & 0.6741 & 0.4395 & 0.7479 & - & - & - & - \\
\hline & Mixed-FEM & - & - & - & 0.7338 & - & - & - & - \\
\hline & Kant et.al. (2007) & -0.6570 & 0.6551 & 0.4683 & 0.7333 & -0.8018 & 0.7995 & 0.6914 & 0.9221 \\
\hline
\end{tabular}

Table 4: Effect of loading and aspect ratio $\mathrm{S}$ on normalized transverse displacement $\bar{w}$, inplane normal stress $\bar{\sigma}_{x}$ and transverse shear stress $\bar{\tau}_{x z}^{\max }$ in an orthotropic beam with MAT-2. (Example-2). 


\begin{tabular}{|c|c|c|c|c|c|c|c|c|c|}
\hline \multirow{2}{*}{ S } & \multirow{2}{*}{ Theory } & \multicolumn{4}{|c|}{ Sinusoidal Load } & \multicolumn{4}{|c|}{ Uniform Load } \\
\hline & & $\bar{\sigma}_{x}^{\mathrm{TOP}}$ & $\bar{\sigma}_{x}^{\mathrm{BOT}}$ & $\bar{\tau}_{x z}^{\max }$ & $\bar{w}$ & $\bar{\sigma}_{x}^{\mathrm{TOP}}$ & $\bar{\sigma}_{x}^{\mathrm{BOT}}$ & $\bar{\tau}_{x z}^{\max }$ & $\bar{w}$ \\
\hline \multirow{9}{*}{4} & NSDT-1 & 0.1930 & -2.1063 & 0.7451 & 4.4279 & 0.2372 & -2.5135 & 1.1766 & 5.5565 \\
\hline & NSDT-2 & 0.1931 & -2.1007 & 0.7453 & 4.4237 & 0.2371 & -2.5016 & 1.1745 & 5.5660 \\
\hline & NSDT-3 & 0.1930 & -2.1000 & 0.7453 & 4.4237 & 0.2374 & -2.5013 & 1.1645 & 5.5600 \\
\hline & NSDT-4 & 0.1930 & -2.1076 & 0.7453 & 4.4237 & 0.2371 & -2.5084 & 1.1758 & 5.5600 \\
\hline & NSDT-5 & 0.1924 & -2.1208 & 0.7479 & 4.3735 & 0.2365 & -2.5270 & 1.2161 & 5.4999 \\
\hline & NSDT-6 & 0.1917 & -2.1312 & 0.7508 & 4.3162 & 0.2369 & -2.5420 & 1.2242 & 5.4308 \\
\hline & HOST & 0.2355 & -1.6825 & 0.7055 & 4.2903 & - & - & - & - \\
\hline & Mixed-FEM & 0.2390 & -1.8711 & 0.6875 & 4.7636 & - & - & - & - \\
\hline & Kant et.al.(2007) & 0.2399 & -1.8762 & 0.6798 & 4.7080 & 0.2905 & 2.2924 & 0.9622 & 5.9005 \\
\hline \multirow{9}{*}{10} & NSDT-1 & 0.1899 & -1.8022 & 0.7381 & 2.9145 & 0.2341 & -2.2097 & 1.1273 & 3.6866 \\
\hline & NSDT-2 & 0.1899 & -1.8023 & 0.7381 & 2.9139 & 0.2341 & -2.2091 & 1.1177 & 3.6859 \\
\hline & NSDT-3 & 0.1899 & -1.8023 & 0.7379 & 2.9139 & 0.2341 & -2.2100 & 1.1177 & 3.6859 \\
\hline & NSDT-4 & 0.1899 & -1.8024 & 0.7379 & 2.9139 & 0.2341 & -2.2102 & 1.1177 & 3.6860 \\
\hline & NSDT-5 & 0.1898 & -1.8049 & 0.7384 & 2.9069 & 0.2340 & -2.2119 & 1.1200 & 3.6773 \\
\hline & NSDT-6 & 0.1896 & -1.8069 & 0.7387 & 2.8988 & 0.2339 & -2.2146 & 1.1224 & 3.6673 \\
\hline & HOST & 0.1973 & -1.7300 & 0.7284 & 2.8965 & - & - & - & - \\
\hline & Mixed-FEM & 0.1977 & -1.7599 & 0.7567 & 1.9540 & - & - & - & - \\
\hline & Kant et.al. (2007) & 0.1983 & -1.7653 & 0.7255 & 2.9611 & 0.2432 & -2.1733 & 1.0738 & 3.7442 \\
\hline
\end{tabular}

Table 5: Effect of loading and aspect ratio on normalized transverse displacement $\bar{w}$, inplane normal stress $\bar{\sigma}_{x}$ and transverse shear stress $\bar{\tau}_{x z}^{\max }$ in a $\left(0^{\mathrm{O}} / 90^{\mathrm{O}}\right)$ beam with MAT-2. (Example-3) 
Uniform Load

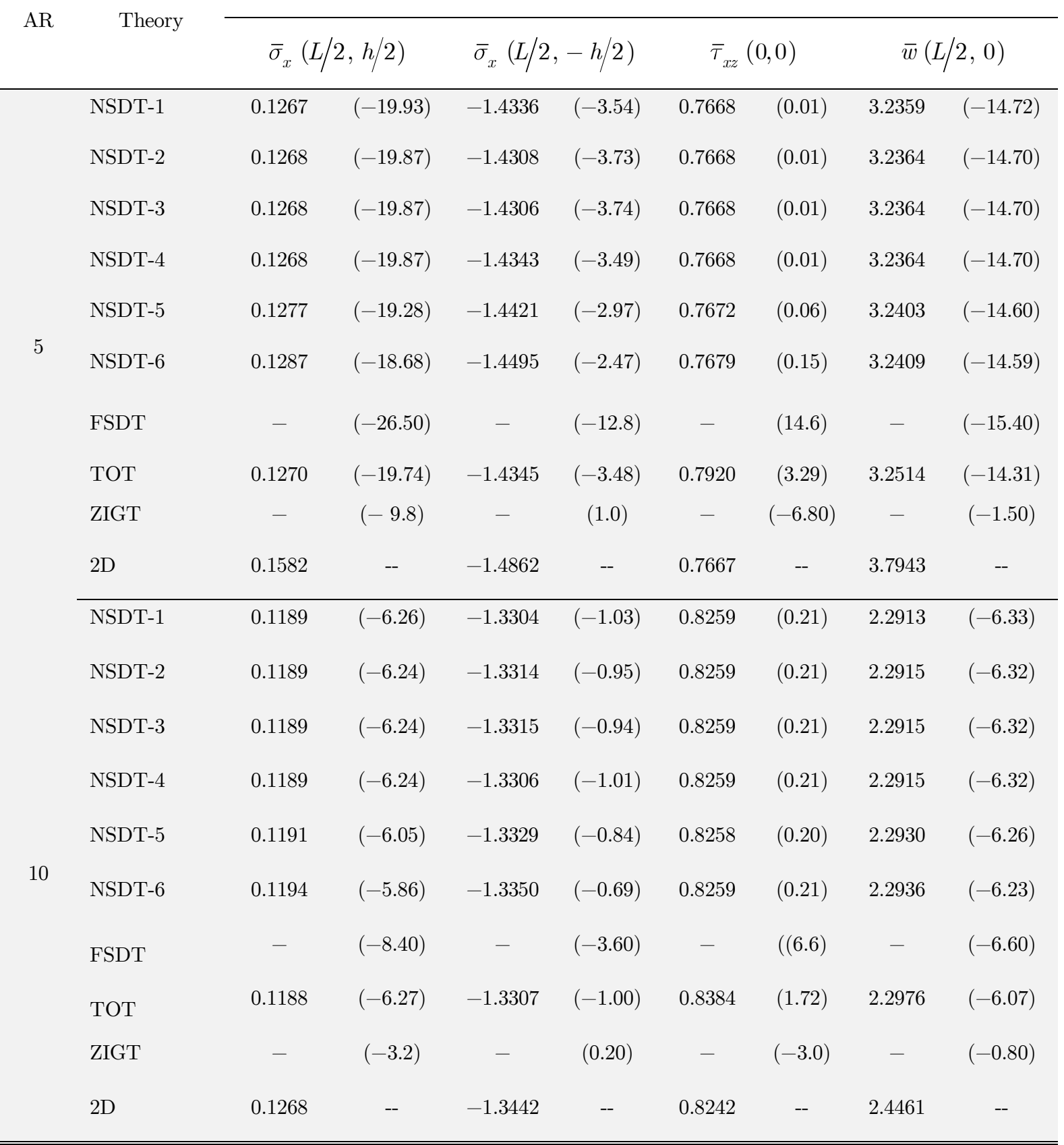

Table 6: Effect of loading and aspect ratio on normalized transverse displacement $\bar{w}$, inplane normal stress $\bar{\sigma}_{x}$ and transverse shear stress $\bar{\tau}_{x z}^{\max }$ in a $\left(0^{\mathrm{O}} / 90^{\mathrm{O}} / 0^{\mathrm{O}} / 90^{\mathrm{O}}\right)$ beam with MAT-3. (Example-4). 
Sinusoidal Load

\begin{tabular}{|c|c|c|c|c|c|c|c|c|c|}
\hline \multirow{2}{*}{$\mathrm{AR}$} & \multirow{2}{*}{ Theory } & & & & & & & & \\
\hline & & \multicolumn{2}{|c|}{$\bar{\sigma}_{x}(L / 2, h / 2)$} & \multicolumn{2}{|c|}{$\bar{\sigma}_{x}(L / 2,-h / 2)$} & \multicolumn{2}{|c|}{$\bar{\tau}_{x z}(0,0)$} & \multicolumn{2}{|c|}{$\bar{w}(L / 2,0)$} \\
\hline \multirow{9}{*}{4} & NSDT-1 & 1.0669 & $(-5.62)$ & -1.0669 & $(-9.29)$ & 0.3890 & $(-1.37)$ & 2.6764 & $(-7.39)$ \\
\hline & NSDT-2 & 1.0698 & $(-5.36)$ & -1.0698 & $(-9.05)$ & 0.3884 & $(-1.52)$ & 2.6789 & $(-7.31)$ \\
\hline & NSDT-3 & 1.0698 & $(-5.36)$ & -1.0698 & $(-9.05)$ & 0.3884 & $(-1.52)$ & 2.6789 & $(-7.31)$ \\
\hline & NSDT-4 & 1.0698 & $(-5.36)$ & -1.0698 & $(-9.05)$ & 0.3884 & $(-1.52)$ & 2.6789 & $(-7.31)$ \\
\hline & NSDT-5 & 1.1012 & $(-2.58)$ & -1.1012 & $(-6.38)$ & 0.3825 & $(-3.02)$ & 2.7029 & $(-6.48)$ \\
\hline & NSDT-6 & 1.1314 & $(0.09)$ & -1.1314 & $(-3.81)$ & 0.3804 & $(-3.55)$ & 2.7205 & $(-5.87)$ \\
\hline & HOST & 0.8713 & $(-22.92)$ & -0.8713 & $(-25.92)$ & 0.4155 & $(5.35)$ & 1.9602 & $(-32.18)$ \\
\hline & Mixed-FEM & 1.1281 & $(4.72)$ & -1.1838 & $(0.65)$ & 0.4000 & $(1.42)$ & 2.8400 & $(-1.73)$ \\
\hline & Kant et.al. (2007) & 1.1304 & & -1.1762 & & 0.3944 & & 2.8901 & \\
\hline \multirow{9}{*}{10} & NSDT-1 & 0.7017 & $(-4.74)$ & -0.7017 & $(-4.67)$ & 0.4335 & $(2.26)$ & 0.8724 & $(-6.52)$ \\
\hline & NSDT-2 & 0.7023 & $(-4.66)$ & -0.7023 & $(-4.59)$ & 0.4334 & $(2.24)$ & 0.8731 & $(-6.44)$ \\
\hline & NSDT-3 & 0.7023 & $(-4.66)$ & -0.7023 & $(-4.59)$ & 0.4334 & $(2.24)$ & 0.8730 & $(-6.45)$ \\
\hline & NSDT-4 & 0.7023 & $(-4.66)$ & -0.7023 & $(-4.59)$ & 0.4334 & $(2.24)$ & 0.8731 & $(-6.44)$ \\
\hline & NSDT-5 & 0.7084 & $(-3.83)$ & -0.7084 & $(-3.76)$ & 0.4322 & $(1.96)$ & 0.8808 & $(-5.62)$ \\
\hline & NSDT-6 & 0.7145 & $(-3.01)$ & -0.7145 & $(-2.94)$ & 0.4309 & $(1.65)$ & 0.8879 & $(-4.86)$ \\
\hline & HOST & 0.6741 & $(-8.48)$ & -0.6741 & $(-8.42)$ & 0.4395 & $(3.68)$ & 0.7479 & $(-19.86)$ \\
\hline & Mixed-FEM & 0.7345 & $(-0.29)$ & -0.7341 & $(-0.22)$ & 0.4251 & $(0.28)$ & 0.9336 & $(0.04)$ \\
\hline & Kant et.al. (2007) & 0.7366 & & -0.7361 & & 0.4239 & & 0.9332 & \\
\hline
\end{tabular}

(\% Errors are quoted in parentheses).

Table 7: Effect of loading and aspect ratio on normalized transverse displacement $\bar{w}$, inplane normal stress $\bar{\sigma}_{x}$ and transverse shear stress $\bar{\tau}_{x z}^{\max }$ in a $\left(0^{\mathrm{o}} / 90^{\mathrm{O}} / 0^{\mathrm{O}}\right)$ beam with MAT-2. (Example-5) 
Sinusoidal Load

\begin{tabular}{|c|c|c|c|c|c|c|c|c|c|}
\hline $\mathrm{AR}$ & Theory & \multicolumn{2}{|c|}{$\bar{\sigma}_{x}(L / 2, h / 2)$} & \multicolumn{2}{|c|}{$\bar{\sigma}_{x}(L / 2,-h / 2)$} & \multicolumn{2}{|c|}{$\bar{\tau}_{x z}(0,0)$} & \multicolumn{2}{|c|}{$\bar{w}(L / 2,0)$} \\
\hline \multirow{7}{*}{4} & NSDT-1 & 2.1311 & $(-10.60)$ & -2.1311 & $(-9.20)$ & 0.3426 & $(0.88)$ & 10.0121 & $(-0.48)$ \\
\hline & NSDT-2 & 2.1283 & $(-10.72)$ & -2.1283 & $(-9.32)$ & 0.3426 & $(0.88)$ & 10.0177 & $(-0.42)$ \\
\hline & NSDT-3 & 2.1280 & $(-10.73)$ & -2.1280 & $(-9.33)$ & 0.3426 & $(0.88)$ & 10.0177 & $(-0.42)$ \\
\hline & NSDT-4 & 2.1340 & $(-10.48)$ & -2.1340 & $(-9.08)$ & 0.3426 & $(0.88)$ & 10.0177 & $(-0.42)$ \\
\hline & NSDT-5 & 2.1626 & $(-9.28)$ & -2.1626 & $(-7.86)$ & 0.3422 & $(0.77)$ & 10.0454 & $(-0.15)$ \\
\hline & NSDT-6 & 2.1821 & $(-8.47)$ & -2.1821 & $(-7.03)$ & 0.3419 & $(0.68)$ & 10.0016 & $(-0.58)$ \\
\hline & Kant et.al. (2007) & 2.3839 & & -2.3470 & & 0.3396 & & 10.0600 & \\
\hline \multirow{7}{*}{10} & NSDT-1 & 1.3875 & $(-3.09)$ & -1.3875 & $(-3.07)$ & 0.3510 & $(0.17)$ & 2.4747 & $(-7.27)$ \\
\hline & NSDT-2 & 1.3895 & $(-2.95)$ & -1.3895 & $(-2.93)$ & 0.3510 & $(0.17)$ & 2.4759 & $(-7.23)$ \\
\hline & NSDT-3 & 1.3897 & $(-2.93)$ & -1.3897 & $(-2.91)$ & 0.3510 & $(0.17)$ & 2.4759 & $(-7.23)$ \\
\hline & NSDT-4 & 1.3880 & $(-3.05)$ & -1.3880 & $(-3.03)$ & 0.3510 & $(0.17)$ & 2.4759 & $(-7.23)$ \\
\hline & NSDT-5 & 1.3939 & $(-2.64)$ & -1.3939 & $(-2.62)$ & 0.3508 & $(0.11)$ & 2.4830 & $(-6.96)$ \\
\hline & NSDT-6 & 1.3969 & $(-2.43)$ & -1.3969 & $(-2.41)$ & 0.3506 & $(0.06)$ & 2.4780 & $(-7.15)$ \\
\hline & Kant et.al. (2007) & 1.4317 & & -1.4314 & & 0.3504 & & 2.6688 & \\
\hline
\end{tabular}

(\% Errors are quoted in parentheses).

Table 8: Effect of loading and aspect ratio on normalized transverse displacement $\bar{w}$, inplane normal stress $\bar{\sigma}_{x}$ and transverse shear stress $\bar{\tau}_{x z}^{\max }$ in a sandwich $\left(0^{\mathrm{O}} /\right.$ core $\left./ 0^{\mathrm{O}}\right)$ beam with MAT-4. (Example-6) 
Uniform Load

\begin{tabular}{|c|c|c|c|c|c|c|c|c|c|}
\hline $\mathrm{AR}$ & Theory & \multicolumn{2}{|c|}{$\bar{\sigma}_{x}(L / 2, h / 2)$} & \multicolumn{2}{|c|}{$\bar{\sigma}_{x}(L / 2,-h / 2)$} & \multicolumn{2}{|c|}{$\bar{\tau}_{x z}(0,0)$} & \multicolumn{2}{|c|}{$\bar{w}(L / 2,0)$} \\
\hline \multirow{9}{*}{5} & NSDT-1 & 1.8945 & $(-3.78)$ & -1.8945 & $(-3.82)$ & 0.50909 & $(-1.03)$ & 7.5238 & $(-4.49)$ \\
\hline & NSDT-2 & 1.8893 & $(-4.04)$ & -1.8893 & $(-4.09)$ & 0.50900 & $(-1.05)$ & 7.5196 & $(-4.55)$ \\
\hline & NSDT-3 & 1.8896 & $(-4.03)$ & -1.8896 & $(-4.07)$ & 0.50901 & $(-1.05)$ & 7.5196 & $(-4.55)$ \\
\hline & NSDT-4 & 1.9852 & $(0.83)$ & -1.8952 & $(-3.79)$ & 0.50899 & $(-1.05)$ & 7.5696 & $(-3.91)$ \\
\hline & NSDT-5 & 1.9015 & $(-3.42)$ & -1.9015 & $(-3.47)$ & 0.50563 & $(-1.70)$ & 7.4556 & $(-5.36)$ \\
\hline & NSDT-6 & 1.9042 & $(-3.29)$ & -1.9042 & $(-3.33)$ & 0.50700 & $(-1.44)$ & 7.3561 & $(-6.62$ \\
\hline & FSDT & - & $(-21.9)$ & - & $(-22.0)$ & - & $(7.2)$ & - & $(-33.1)$ \\
\hline & ZIGT & - & $(0.1)$ & - & $(0.1)$ & - & $(-1.0)$ & - & $(-0.1)$ \\
\hline & $2 \mathrm{D}$ & 1.9689 & & -1.9698 & & 0.51439 & & 7.8778 & \\
\hline \multirow{9}{*}{10} & NSDT-1 & 1.6280 & $(-1.03)$ & -1.6280 & $(-1.04)$ & 0.53120 & $(-0.49)$ & 3.1543 & $(-2.90)$ \\
\hline & NSDT-2 & 1.6308 & $(-0.86)$ & -1.6308 & $(-0.87)$ & 0.53115 & $(-0.50)$ & 3.1534 & $(-2.93)$ \\
\hline & NSDT-3 & 1.6309 & $(-0.85)$ & -1.6309 & $(-0.86)$ & 0.53115 & $(-0.50)$ & 3.1534 & $(-2.93)$ \\
\hline & NSDT-4 & 1.6263 & $(-1.13)$ & -1.6263 & $(-1.14)$ & 0.53115 & $(-0.50)$ & 3.1534 & $(-2.93)$ \\
\hline & NSDT-5 & 1.6282 & $(-1.02)$ & -1.6282 & $(-1.03)$ & 0.53063 & $(-0.60)$ & 3.1390 & $(-3.37)$ \\
\hline & NSDT-6 & 1.6295 & $(-0.94)$ & -1.6295 & $(-0.95)$ & 0.53013 & $(-0.69)$ & 3.1160 & $(-4.08)$ \\
\hline & FSDT & - & $(-6.6)$ & - & $(-6.6)$ & - & $(-3.3)$ & - & $(-20.5)$ \\
\hline & ZIGT & - & $(0.0)$ & - & $(0.0)$ & - & $(-0.5)$ & - & $(-0.1)$ \\
\hline & $2 \mathrm{D}$ & 1.6449 & & -1.6451 & & 0.53383 & & 3.2486 & \\
\hline
\end{tabular}

(\% Errors are quoted in parentheses).

Table 9: Normalized transverse displacement $\bar{w}$, inplane normal stress $\bar{\sigma}_{x}$ and transverse shear stress $\bar{\tau}_{x z}^{\max }$ in a sandwich beam with graphite epoxy faces and soft core under uniform load with MAT-5. (Example-7). 


\begin{tabular}{|c|c|c|c|c|c|c|c|c|c|}
\hline \multirow{2}{*}{$\mathrm{S}$} & \multirow{2}{*}{ Theory } & \multicolumn{4}{|c|}{ Example 6 (MAT-4) } & \multicolumn{4}{|c|}{ Example 7 (MAT-5) } \\
\hline & & $\bar{\sigma}_{x}^{T o p}$ & $\bar{\sigma}_{x}^{B o t}$ & $\bar{\tau}_{x z}^{\max }$ & $\bar{w}$ & $\bar{\sigma}_{x}^{T o p}$ & $\bar{\sigma}_{x}^{B o t}$ & $\bar{\tau}_{x z}(0,0)$ & $\bar{w}$ \\
\hline \multirow{10}{*}{10} & NSDT-1 & -2.75 & -2.92 & 0.74 & -7.23 & -1.03 & -1.04 & -0.49 & -2.90 \\
\hline & NSDT-2 & -2.61 & -2.78 & 0.74 & -7.19 & -0.86 & -0.87 & -0.50 & -2.93 \\
\hline & NSDT-3 & -2.60 & -2.76 & 0.74 & -7.19 & -0.85 & -0.86 & -0.50 & -2.93 \\
\hline & NSDT-4 & -2.73 & -2.90 & 0.74 & -7.19 & -1.13 & -1.14 & -0.50 & -2.93 \\
\hline & NSDT-5 & -2.41 & -2.58 & 0.66 & -6.92 & -1.02 & -1.03 & -0.60 & -3.37 \\
\hline & NSDT-6 & -2.20 & -2.37 & 0.60 & -7.10 & -0.94 & -0.95 & -0.69 & -4.08 \\
\hline & FSDT & - & - & - & - & -6.6 & -6.6 & -3.3 & -20.5 \\
\hline & ZIGT & - & - & - & - & 0.0 & 0.0 & -0.5 & -0.1 \\
\hline & $2 \mathrm{D}$ & - & - & - & - & $(1.6449)$ & $(-1.6451)$ & $(0.53383)$ & $(3.2486)$ \\
\hline & Kant et.al.(2007) & $(1.7260)$ & $(1.7290)$ & $(0.5240)$ & $(3.33)$ & - & - & - & - \\
\hline \multirow{10}{*}{20} & NSDT-1 & -0.83 & -0.85 & 1.37 & -3.46 & -0.27 & -0.27 & -0.23 & -1.16 \\
\hline & NSDT-2 & -0.64 & -0.66 & 1.37 & -3.44 & 0.08 & 0.08 & -0.24 & -1.17 \\
\hline & NSDT-3 & -0.60 & -0.62 & 1.37 & -3.44 & 0.08 & 0.08 & -0.24 & -1.17 \\
\hline & NSDT-4 & -0.82 & -0.84 & 1.37 & -3.44 & -0.30 & -0.30 & -0.24 & -1.17 \\
\hline & NSDT-5 & -0.70 & -0.72 & 1.33 & -3.32 & -0.22 & -0.22 & -0.29 & -1.33 \\
\hline & NSDT-6 & -0.63 & -0.65 & 1.31 & -3.42 & -0.15 & -0.15 & -0.33 & -1.61 \\
\hline & FSDT & - & - & - & - & -1.7 & -1.7 & -1.5 & -8.1 \\
\hline & ZIGT & - & - & - & - & 0.0 & 0.0 & -0.2 & -0.1 \\
\hline & $2 \mathrm{D}$ & - & - & - & - & $(1.5639)$ & $(1.5639)$ & $(0.54351)$ & $(2.0770)$ \\
\hline & Kant et.al.(2007) & (1.5833) & $(-1.5836)$ & $(0.5534)$ & (1.7935) & - & - & - & - \\
\hline
\end{tabular}

(Values of parameters used for comparison are quoted in parentheses)

Table 10: Effect of 'softness' of sandwich core by comparing percentage errors of normalized displacement and stresses in sandwich beams in Example 6 and 7 under uniform load. 
Variation of transverse displacement does not remain constant through the thickness of deep beams even for isotropic beam. Also, the displacement towards the surface of loading is higher compared to bottom face. This effect is attributed to the phenomenon of contact mechanics in the beam and is completely discarded in shear deformation theories without incorporation of normal deformability. This effect is accounted in the present theory. However, it is found that the deformation is symmetric about the neutral axis, since thickness-coordinate terms in expression for $w$ are even functions.

In-plane normal stress is evaluated directly from the constitutive relations and straindisplacement relations. Although the maximum values of the in-plane normal stresses are underpredicted compared to semi-analytical solution, it has been noted that the deviation manifests only at the surfaces of the beams; the values concur to semi-analytical results just away from the surface. It can be observed that the results are in good agreement with semi-analytical solutions compared to HOST and are close to rigorous theories like mixed-FEM.

Transverse shear stress in beam can be evaluated using constitutive relations (CR) or by using equilibrium equations (EE). Transverse shear stress will be discontinuous at the inter-laminar surface with use of CRs. However, EEs can be effectively used to overcome this drawback resulting in a continuous stress variation through the thickness. The values of shear stress reported in present paper are evaluated using EEs. The present theory predicts the values that are in good agreement with semi-analytical solutions. It can be observed from Table 6, that for unsymmetric cross-ply laminates with aspect ratio 5 , the percentage error is $0.01 \%$ for NSDT-1 to 4 ; whereas for NSDT-5 it is $0.06 \%$ and for NSDT-6 it is $0.15 \%$. For same case, third order theory (TOT) gives overprediction of $3.29 \%$ and zigzag theory (ZIGT) under-predict the value by $6.8 \%$.

This is consistently found for symmetric cross-ply as well as sandwich beam. Accuracy of shear stress increases for beams with transversely flexible layers. This effect is depicted in Table 10 and it can be observed that percentage error for NSDT- 1 to 4 is $0.74 \%$ with MAT-4; and reduces to nearly $-0.50 \%$ for MAT-5. Accuracy of results further increases with increase in aspect ratio of beams. 


\begin{tabular}{llcl}
\hline \hline $\boldsymbol{\Delta}$ & & & NSDT-6 \\
NSDT-1 & $\nabla$ & Kant et.al. \\
NSDT-2 & $\bigcirc$ & Desai and Ramtekkar (2002) \\
NSDT-3 & & Shimpi and Ghugal (1999) \\
NSDT-4 & & \\
\hline NSDT-5 & & \\
\hline \hline
\end{tabular}

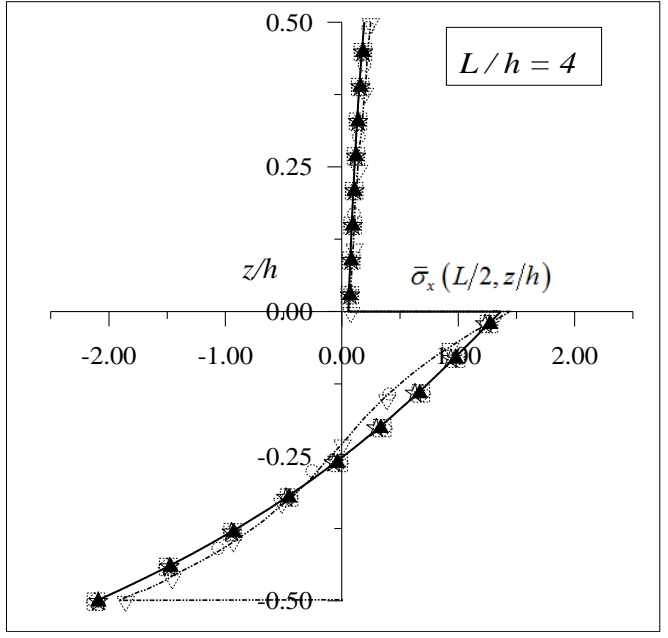

(a)

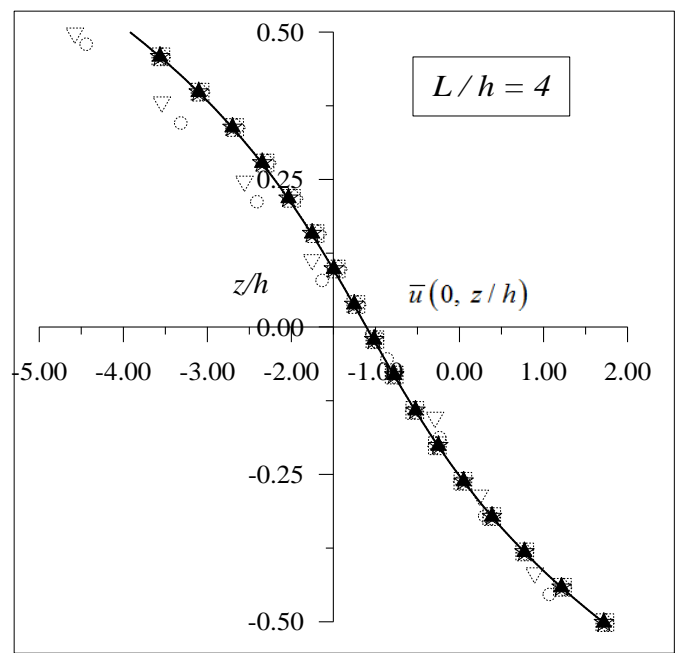

(c)

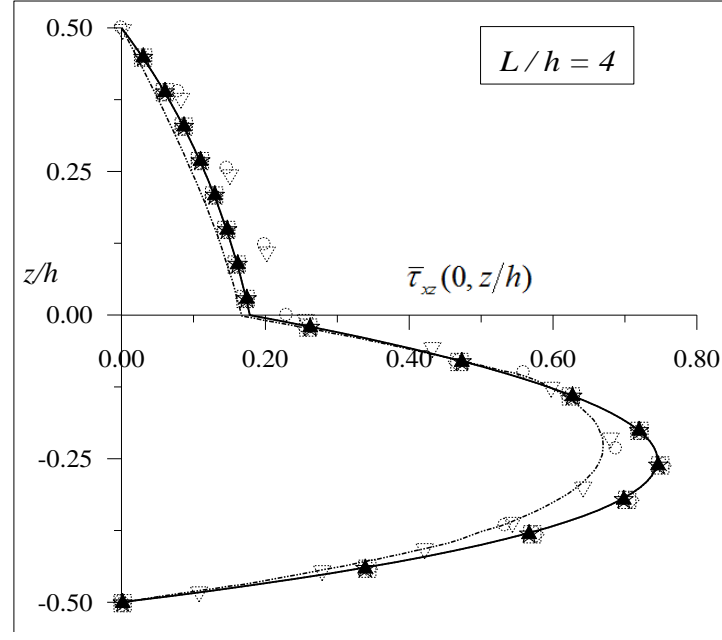

(b)

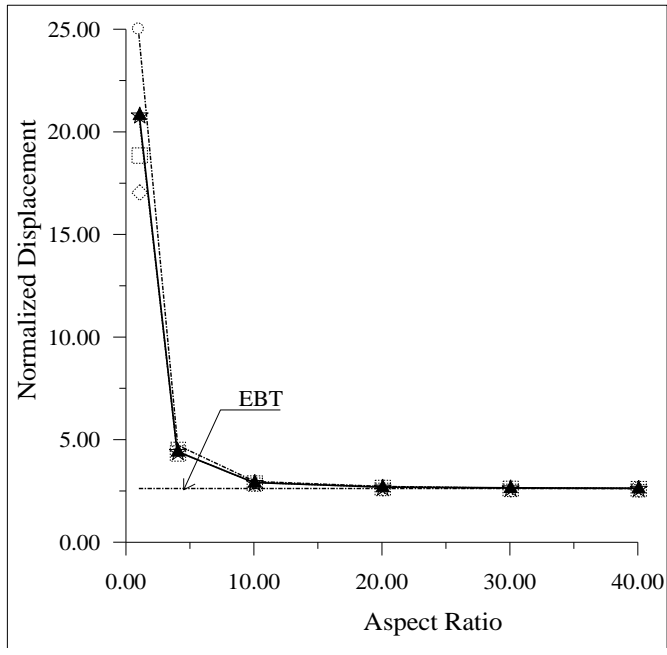

(d)

Figure 4: Variation of normalized (a) inplane stress $\bar{\sigma}_{x}$ at $(0, \mathrm{z}),(\mathrm{b})$ transverse stress $\bar{\tau}_{x z}$, (c) inplane displacement $\bar{u}(0, z / h)$ through the thickness and (d) transverse displacement $\bar{w}(L / 2 /, 0)$ in a $\left(0^{0} / 90^{0}\right)$ beam subjected to SSL. 


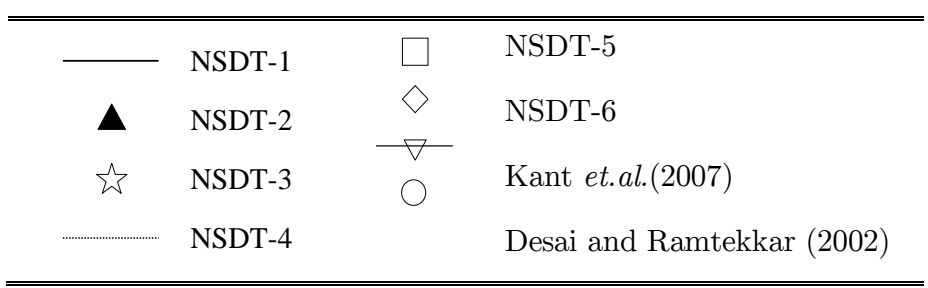

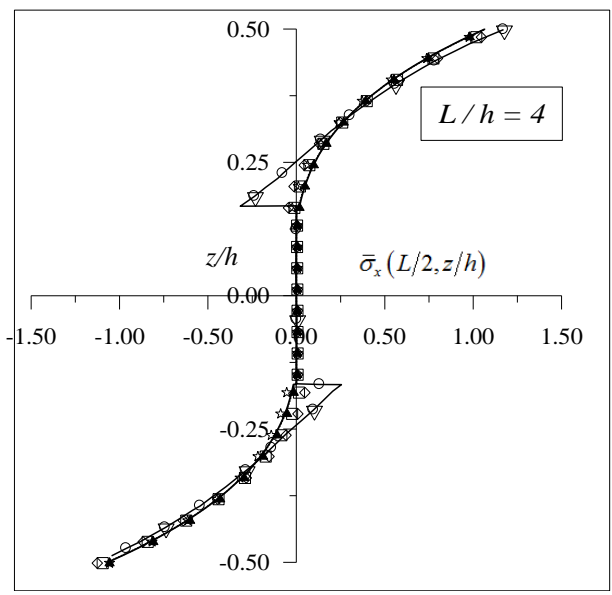

(a)

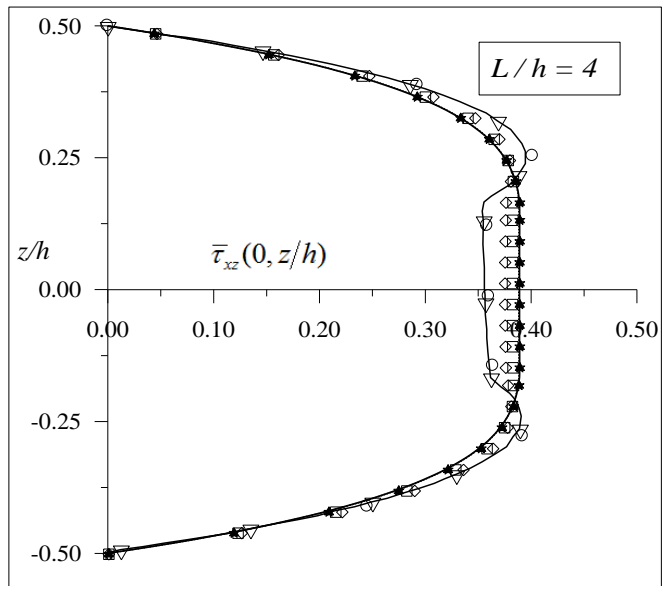

(b)

Figure 5: Variation of normalized (a) inplane stress $\bar{\sigma}_{x}$ at $(0, \mathrm{z})$ and (b) transverse stress $\bar{\tau}_{x z}$ through the thickness $\left(\left(0^{0} / 90^{0} / 0^{0}\right)\right.$ beam subjected to sinusoidal load for aspect ratio 4 .

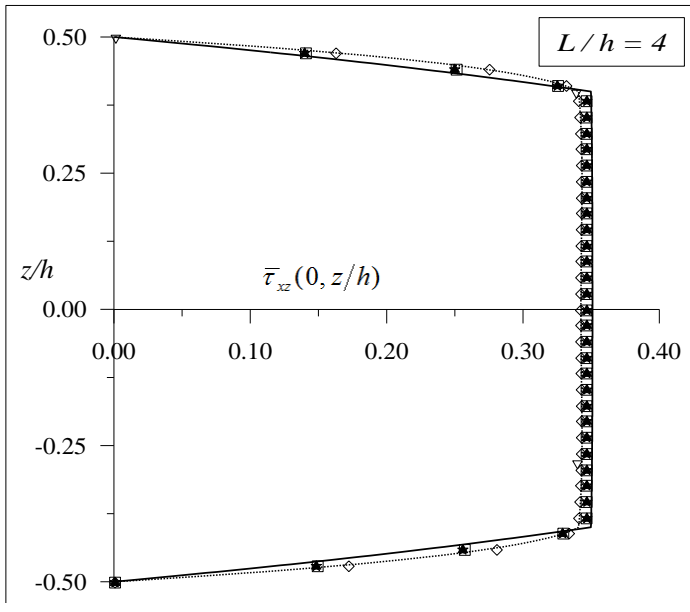

(a)

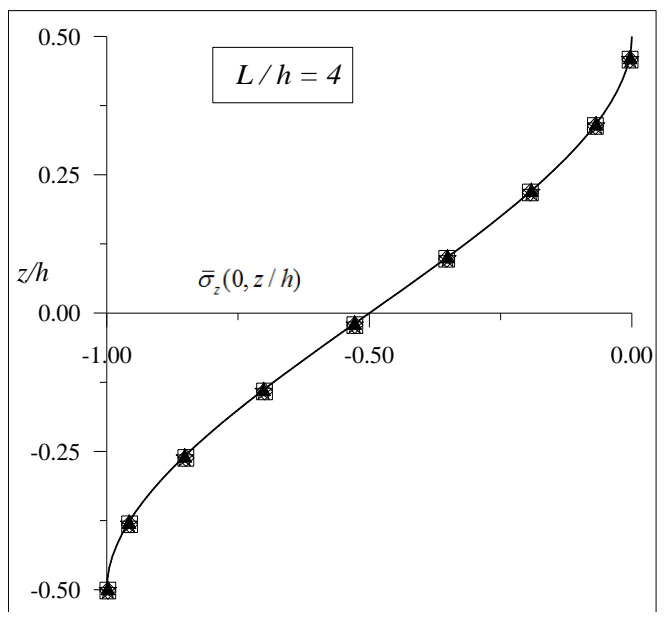

(b)

Figure 6: Variation of normalized (a) transverse shear stress $\bar{\tau}_{x z}$ and (b) transverse normal stress $\bar{\sigma}_{z}$ at $(0, z)$ through the thickness of $\left(0^{0} /\right.$ core $\left./ 0^{0}\right)$ beam subjected to sinusoidal load for aspect ratio 4 . 


\section{CONCLUSIONS}

In the present paper, a novel, generalized Normal and Shear Deformation Theory (NSDT) is developed for incorporating shear deformations as well as normal deformations consistent with different warping functions. The present theory is based on the concept of improvement in the kinematics of beam with inclusion of normal deformability. It is a displacement based refined shear and normal deformation theory, where the shear deformation and transverse flexibility in the beam are properly accounted. The governing differential equations and the associated boundary conditions are variationally consistent. The flexural behaviors of thick laminated and sandwich beams under plane stress conditions are studies using NSDT and the results obtained are compared with those of other theories. The important observations several features of the present theory are given below:

1. The results obtained by the present theory are accurate as seen from the comparison with available results and are in general, superior to those of other refined shear deformation theories.

2. NSDT predicts displacements and stresses accurately than other higher order theories for beams with transversely flexible layers.

3. The present theory predicts in-plane stresses with good accuracy for very thick beam.

4. Transverse shear stresses obtained either by constitutive relations or by integrating equilibrium equations satisfy shear stress free conditions on the top and bottom surfaces of the beam.

5. Through-the-thickness distribution of transverse stresses is predicted accurately by NSDT.

6. The theory obviates the need of shear correction factor.

\section{References}

Allen, H.G. (1969). Analysis and design of structural sandwich panels, Pergamon Press (Oxford).

Ambartsumian, S.A. (1958). On the theory of bending plates, Izv Otd Tech Nauk AN SSSR, 5:69-77.

Arbind, E., Reddy, J.N. and Shrinivasa, A.R.. (2014). Modified coupled stress-based third-order theory for nonlinear analysis of functionally graded beams, Latin American Journal of Solids and Structures. 11:459-87.

Bambole, A.N. and Desai, Y.M. (2007). Hybrid-interface finite element for laminated composite and sandwich beams, Finite Elements in Analysis and Design, 43:1023 - 1036.

Bickford, W.B., (1982). A consistent higher order beam theory", Developments Theory of Applied Mechanics;11:13742.

Carrera, E., Filippi, M. and Zappino, E. (2013). Laminated beam analysis by polynomial, trigonometric, exponential and zig-zag theories, European Journal of Mechanics A /Solids 41:58-69.

Desai, Y. M. and Ramtekkar, G.S. (2002). Mixed finite element model for laminated composite beams, Structural Engineering and mechanics-An International Journal, 13:261-276.

Frostig, Y., Baruch, M., Vilnay, O. and Sheinman, I. (1992). High order theory for sandwich beams behavior with transversely flexible core, J. Eng. Mech., 118:1026-1043.

Kant, T. and Manjunatha BS, (1989). Refined theories for composite and sandwich beams with C0 finite elements, Computers and Structures, 33: 755-64. 
Kant, T., Pendhari, S.S. and Desai, Y.M. (2007). On accurate stress analysis of composite and sandwich narrow beams, International Journal for Computational Methods in Engineering Science and Mechanics, 8:165-177.

Kapuria, S., Dumir, P.C., Jain, N.K. (2004). Assessment of zigzag theory for static loading, buckling, free and forced response of composite and sandwich beams, Composite Structures 64:317-327.

Karama, M., Afaq, K.S. and Mistou, S. (2003). Mechanical behavior of laminated composite beam by new multilayered laminated composite structures model with transverse stress continuity, International Journal of Solids and Structures, 40:1525-46,.

Khdier, A.A. and Reddy, J. N., (1997). An exact solution for bending of thin and thick cross-ply laminated beams, Composite Structures 37:195-203.

Levinson, M.(1980). An accurate simple theory of the statics and dynamics of elastic plates, Mech. Res. Commun. $7: 343-350$.

Levinson, M.(1981). A New rectangular beam theory, J. Sound and Vibration, 74:81-87.

Lo, K.H., Christensen, R.M., Wu, E.M. (1977). A higher order theory for deformations, Part 2: laminated plates, ASME Trans. Journal of Applied Mechanics, 44:669-76.

Manjunatha, B.S. and Kant T.( 1993). Different numerical techniques for the estimation of multiaxial stresses in symmetric / unsymmetric composite and sandwich beams with refined theories, J. Reinforced Plastics and Composites $12: 2-37$.

Murthy, M.V.V.(1981). An improved transverse shear deformation theory for laminated anisotropic plates, NASA Technical Paper.

Noor, A.K., Burton, W.S. and Peters, J.K.( 1994). Hierarchical adaptive modeling of structural sandwiched and multilayered composite panels, Applied Numerical Mathematics 14:69-90.

Pagano, N.J. (1969). Exact solutions for composite laminates in cylindrical bending, J. Composite Materials, 3:398411.

Panc, V. (1975). Theories of Elastic Plates, Academia (Prague).

Reddy, J.N., (1991). A simple higher-order theory for laminated composites, J. Applied Mechanics; 51: 45-52.

Reissner, E. (1975). On transverse bending of plates, including the effect of transverse shear deformation, Int. J. Solids and Structures, 11:569-573.

Shimpi, R.P. and Ghugal, Y. M., (1999). A layerwise trigonometric shear deformation theory for two layered crossply laminated beams, J. Reinforced Plastic Composites, 18:1516-1543.

Soldatos, K.P.(1992).A transverse shear deformation theory for homogeneous monoclinic plates," Act Mech, 94:195200.

Soldatos, K.P. and Elishakoff, I.( 1992). A transverse shear and normal deformable orthotropic beam theory, Journal of Sound and Vibration, 3: 528-533.

Timoshenko, S.P. (1921). On the correction for shear of the differential equation for transverse vibrations of prismatic bars, Philosophical Magazine, Series 6; 41:742-46.

Touratier, M., "An efficient standard plate theory," Journal of Applied Mechanics, 51, pp.745-752, 1991.

Vinson, J.R. and Chou, T.W.( 1975). Composite materials and their use in structures, Applied Science,( London).

Zenkour, A.M., (1999). Transverse shear and normal deformation theory for bending analysis of laminated and sandwich elastic beams, Mech. Composite Materials and Structures, 6:267-283. 